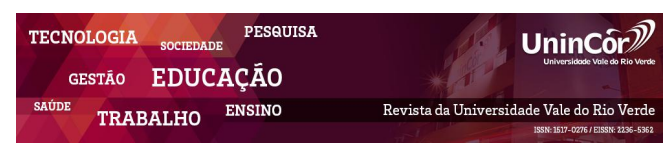

Revista da Universidade Vale do Rio Verde ISSN: 1517-0276 / EISSN: 2236-5362 Vol. 17 | n. 2 | Ano 2019

Cristiano Max Pereira Pinheiro Universidade Feevale maxrs@feevale.br

Mauricio Barth

Universidade Feevale $\underline{\operatorname{maxrs} @ \text { feevale.br }}$

Rafaela Wecker

Universidade Feevale rafaelaweckerc@gmail.com

Mikaela de Souza Universidade Feevale mikaela@,feevale.br

\section{CONVERGÊNCIAS ENTRE PUBLICIDADE E MODA NO BRASIL: UM ESTUDO DA MARCA ELLUS}

\section{RESUMO}

Este estudo tem como objetivo analisar a contribuição da publicidade para a construção de uma identidade única na moda brasileira. Para tal, apresenta-se um estudo da marca Ellus Jeans Deluxe, que participou ativamente da história da moda no Brasil, bem como investiu no mercado publicitário em todas as suas coleções. O resgate bibliográfico ocorreu a partir de autores como Sant'Anna (2002), Sampaio (2003), Martins (1999), Lobassi (2016) e Cadena (2001), que discorrem sobre a publicidade explicando seus conceitos e definições. Os autores Pollini (2007), Cidreira (2005), Spengler (1993), Palomino (2003), Cosgrave (2012), Lipovetsky (1989), Neira (2016) e outros foram utilizados para aprofundar os conceitos sobre moda. Para conduzir o estudo de caso e apresentar as afirmativas da hipótese deste ensaio, apresenta-se a análise de cinco campanhas, referente às cinco décadas da marca Ellus.

Palavras-chave: Publicidade. Moda. Ellus.

\section{CONVERGENCES BETWEEN ADVERTISING AND FASHION IN BRAZIL: A STUDY OF THE ELLUS BRAND}

\begin{abstract}
This study aims to discover the contribution of advertising to construction of a unique identity for Brazilian fashion. For this, a study of the brand Ellus Jeans Deluxe, that participated actively in the history of the fashion in Brazil, as well as invested in the advertising market in all its collections. The bibliographic retrieval was carried out by authors such as Sant'Anna (2002), Sampaio (2003), Martins (1999), Lobassi (2016) and Cadena (2001) who discuss advertising and explain their concepts and definitions. The authors Pollini (2007), Cidreira (2005), Spengler (1993), Palomino (2003), Cosgrave (2012), Lipovetsky (1989), Neira (2016) and others were used to deepen the concepts about fashion. To conduct the case study, and present the assumptions of the hypothesis of this essay, we present the analysis of five campaigns, referring to the five decades of the Ellus brand.
\end{abstract}

Keywords: Advertising. Fashion. Ellus. 


\section{INTRODUÇÃO}

Moda e publicidade são assuntos conectados, pois, comumente, são relacionados em um mesmo contexto. Enquanto a moda é responsável por criar peças e conceitos indumentários, a publicidade é responsável não apenas por anunciar o produto ao mercado, mas, também, influenciar o consumidor a viver a moda além do sentido de vestir. No Brasil, a publicidade teve uma significativa importância para a indústria têxtil, pois ajudou a moldar padrões exclusivamente nacionais no mercado, atendendo às necessidades da sociedade. Este ensaio busca compreender qual a importância da publicidade para a construção de uma identidade para a moda brasileira.

Com um cenário consolidado no mercado de moda, o Brasil possui um catálogo de marcas que seguiram a trajetória de história da indústria no país - algumas, inclusive, destacamse até hoje. O objeto de estudo deste caso é a marca Ellus, Fundada em 1972 e pioneira no mercado Jeanswear no Brasil, a marca sempre buscou inovação, se tornando protagonista das principais mudanças no mundo da moda no Brasil.

Parte-se do pressuposto que, a partir da ruptura iniciada nos anos 20, a moda brasileira evoluiu, permeando valores que são destacados até hoje, consolidando marcas e conceitos dentro e fora do seu território. O mercado de moda brasileiro, que ainda se encontra em constante evolução, atualmente, traz uma identidade própria, abrindo mão de padrões estrangeiros e, ainda, fazendo com que seu padrão seja ousado e conhecido mundo afora. Criando desejos e necessidades, a publicidade construiu este caminho para a moda nacional, através da disseminação de uma cultura de consumo própria.

\section{PUBLICIDADE: CONCEITOS E DEFINIÇÕES}

Os conceitos de publicidade e de propaganda podem ser explicados com significados diferentes, dotados de pequenas peculiaridades entre si. Sant'Anna (2002, p.75) afirma que publicidade é a forma de anunciar algo e propaganda é a forma de tentar implementar uma ideia ou conceito já existente. Sendo assim, atualmente, mesmo não sendo sinônimos os termos publicidade e propaganda são usados como equivalentes.

Em suma, a publicidade tem o objetivo de divulgar determinado produto ou serviço de uma marca, para que o público tenha necessidade de adquiri-lo. Para Sampaio (2003, p.26): “a propaganda pode ser definida como a manipulação planejada da comunicação, visando, pela persuasão, promover comportamentos em benefício do anunciante que a utiliza". Sendo assim, percebe-se que a publicidade é um processo, que tem como objetivo o princípio de que o consumidor traga um benefício ao anunciante, seja adquirindo seu produto, seja contratando seu serviço, ou engajando em alguma causa. Em resumo, que o consumidor realize uma ação proposta por determinada marca.

Segundo Martins (1999, p. 37), foi após a Segunda Guerra Mundial que a propaganda como técnica de persuasão teve surgimento e, no final da década de 50, o crescimento acelerado de novos meios de comunicação foi um processo colaborativo para o seu desenvolvimento, pois 
possibilitou novas técnicas e manifestações estéticas na propaganda.

A publicidade possui características particulares, que são influenciadas pela cultura do meio em que está inserida. Partindo de sua definição e sua origem e entendendo a prática como recente na história mundial, faz-se necessário contextualizar a prática no Brasil, demonstrando suas características e evoluções no decorrer da história do país.

\subsection{A Publicidade no Brasil}

Caracterizada pelo seu apelo criativo, a publicidade brasileira foi considerada a terceira maior potência mundial em criação publicitária nos anos 90 (LOBASSI, [s.d.]). Contudo, para chegar ao nível em que se encontra atualmente, obteve uma série de transformações históricas, evoluindo com o contexto da sociedade brasileira.

Em sua primeira fase, caracterizou-se pela oralidade e por anúncios escritos em forma de classificados, sem serem, contudo, dotados de quaisquer técnicas de persuasão (SILVA; LOPES, 2007). As características desta prática no país iniciaram suas transformações a partir de 1900, primeiros anos do período da República Velha. Segundo Cadena (2001, p. 12), neste período as velhas cidades se expandem, a população se multiplica por conta do êxodo rural e surgem assim novos nichos de consumo.

A transformação ocorre também nos meios de comunicação. Para Cadena (2001, p.12), nesta época aperfeiçoaram-se os veículos de comunicação e a mídia de massa passa a ser uma necessidade, surgindo novas formas de anúncio, como os bondes e os cartões postais. Contudo, o surgimento das revistas ilustradas orientou o sentido da imprensa para este tipo de mídia, dando um novo conceito à forma de anunciar. A Revista da Semana foi a primeira a ser lançada, em 1900, seguida por O Malho, Fon-Fon, A careta, entre outras (MARCONDES; RAMOS, 1995).

A venda dos anúncios ocorria por parte dos agenciadores de propaganda e, segundo Cadena (2001, p.40), em torno de cinquenta destes profissionais atuavam no Brasil com escritórios estabelecidos até 1913, ano em que surge, em São Paulo, a Castaldi \& Benatton, posteriormente denominada A Eclética, a primeira empresa que pode ser denominada como agência de publicidade no Brasil (MARCONDES; RAMOS, 1995).

No entanto, a partir da década de 20, com a instalação de indústrias e marcas norte americanas no país, chega também a técnica americana de propaganda comercial (MARCONDES; RAMOS, 1995). A General Motors foi a pioneira em possuir uma divisão de propaganda, com 34 profissionais, os quais disseminaram princípios da publicidade moderna e introduziram na propaganda brasileira $o$ chamado apelo de vendas (CADENA, 2001).

No ano de 1922, é inaugurado o sinal de rádio no Brasil, mas a tônica da publicidade na era do rádio acontece a partir dos anos 30 , onde são veiculadas, de forma simples, apenas locuções de textos - não havendo sequer patrocínios de programas. Em 1933, acontece o estopim e surgem os spots, os programas associados às marcas e os jingles (MARCONDES; RAMOS, 1995, p.39).

No ano de 1950, inaugura-se em São Paulo a TV Tupi (MARCONDES; RAMOS, 1995), sendo a televisão um marco importante, pois com o desenvolvimento da linguagem deste 
meio, também se desenvolveu a linguagem da publicidade (SILVA; LOPES, 2007). No ano seguinte, segundo Marcondes (1995, p. 53), é fundada em São Paulo a Escola Superior de Propaganda, acontecimento este apontado pelo autor como sinal de que a profissão estava amadurecendo.

$\mathrm{Na}$ década de 60 , as agências brasileiras passaram a ter mais importância, o setor percebeu o verdadeiro valor da criatividade e o apelo racional é substituído pelo apelo emocional (SILVA; LOPES, 2007). Já os anos 70 são marcados por contradições, de um lado a censura limitando a criação e de outro o estímulo por parte de concursos e festivais de propaganda, tanto nacionais quanto no exterior (CADENA, 2001). As transformações nos veículos de comunicação também são destaques desta década. A televisão em cores chega ao país e atinge um grande número de audiência, o rádio toma novas dimensões com o surgimento das emissoras FM e o outdoor é recolocado no mercado (CADENA, 2001).

Os próximos anos são marcados pelo avanço tecnológico. Nas décadas de 80 e 90 percebe-se o desenvolvimento da linguagem escrita e persuasiva e também da linguagem visual, esta ocasionada pela origem de novos softwares e equipamentos tecnológicos (SILVA; LOPES, 2007). Contudo, apesar dos grandes avanços tecnológicos, os anos 90 foram marcados por uma forte crise econômica - e posteriormente cultural - resultante da falta de dinheiro. No fim da década, a implantação do Plano Real e também a criação de órgãos, como o Conar (Conselho Nacional de Autorregulamentação Publicitária), ajudaram o mercado a se reerguer (CADENA, 2001).
Para Cadena (2001, p. 235), nos anos 2000 a informática passa a ser item indispensável, e a internet surge como um veículo revolucionário, do qual a propaganda tem dificuldades para se adequar. A publicidade no Brasil, por sua vez, permanece em constante evolução até os dias atuais, segmentando-se conforme os avanços tecnológicos, sociais e culturais do país.

\section{MODA: CONCEITOS E DEFINIÇÕES}

O melhor conceito de moda é o que a define como uma forma atual de vestuário. Este conceito não se aplica apenas a utilizar uma determinada vestimenta, seguir determinado estilo ou utilizar as roupas do momento. Para Spengler (1993, p. 24), o papel político, econômico e principalmente sociocultural da moda é imensurável. Sendo assim, é através da vestimenta que se refletem expressões, emoções e também conceitos, pois é através dela que mostra-se a personalidade do indivíduo. Segundo Palomino (2003, p.14), a moda é um sistema, que segue conforme o tipo de roupa e o tempo cronológico, que contempla as vestimentas do dia a dia a um contexto político e sociológico, muito maior do que apenas "estar na moda", e que vai além do vestuário.

Para compreender melhor o que é a moda, é importante compreender a sua evolução, que ocorre simultaneamente com a evolução da sociedade. Palomino (2003, p.14) explica que, ao analisar as vestimentas nos anos 70, 80 e 90, por exemplo, encontram-se diferenças entre o que os indivíduos utilizavam em cada década, e que estas diferenças são a moda, pois ela é um reflexo do comportamento da sociedade. 
O desenvolvimento de moda, segundo Pollini (2007, p.16), aconteceu pelo encadeamento histórico ocorrido a partir do final da Idade Média até a chegada do século XIX, período em que se pode, efetivamente, começar a conceituar a moda como percebida atualmente.

Para Cosgrave (2012, p.13), a vida e religião dos egípcios permaneciam mutáveis durante os tempos, e toda esta tradição era refletida na indumentária. Já para Lipovetsky (1989, p.69), foi apenas na metade do século XIX que a moda, como percebida nos dias atuais, começou a ser observada, devido ao progresso tecnológico, denominando-se este período de moda moderna.

O desenvolvimento da tecnologia na indústria têxtil, com a Revolução Industrial, conduziu a indústria da moda para um crescimento constante e o aumento na qualidade de produção. Em 1846, a máquina de costura foi inventada e patenteada por Isaac Singer. Esta e outras inovações melhoraram e aceleraram a produção de roupas prontas, que estavam disponíveis em certas lojas de Paris (Cosgrave, 2012, p.193).

Neste período, a moda começou a criar seu conceito sociocultural, caracterizado pelo status que as compras de roupas em lojas especializadas, que eram raras na época, traziam para a sociedade burguesa. O século XIX representou um período onde as maneiras de pensar e de vestir se modificaram, onde o vestuário passou a ter uma produção mais rápida e barata e a sociedade burguesa encontrava ali a ostentação de suas novidades estéticas (POLLINI, 2007).

Após o estopim ocorrido no século XIX, alavancado pela Revolução Industrial, a moda evoluiu - e continua evoluindo - a partir das mudanças ocorridas na sociedade, sendo um reflexo do corpo social até os dias atuais.

\subsection{A Moda no Brasil}

O debate em torno de um conceito de uma moda brasileira tem suas origens a partir de meados dos anos 20. Segundo Neira (2008, p.02), a partir desta década, as indústrias têxteis nacionais começaram a competir com as indústrias estrangeiras. Além do forte crescimento industrial, o país também passava por uma forte transformação cultural artística, através do movimento modernista de 1922. A moda, neste período, se tornou parte sedutora do movimento, consagrando os artistas que o lideravam, tornando-os referência em estilo (CHATAIGNIER, 2010).

$\mathrm{Na}$ década de 30, acontece o surgimento das casas de magazine, inspiradas nas maisons francesas, que tinham o objetivo de comercializar tecidos e, principalmente, roupas já produzidas, por sua vez, em menor escala (PRADO; BRAGA, 2011). Destas casas, a mais irreverente era a Casa Canadá, localizada na cidade do Rio de Janeiro. Ainda na década de 30, é introduzido no Brasil o hábito dos desfiles de moda, que ocorriam no Hotel Esplanada e no Teatro Municipal. Este hábito foi incorporado pela grife Madame Rosita (FAÇANHA, 2016).

Com o estopim da Segunda Guerra Mundial, mesmo com uma participação pouco significativa, o Brasil sentiu os reflexos na indústria têxtil. O racionamento dos tecidos, por conta da redução da importação, fez com que as maisons confeccionassem roupas próprias gradativamente (KUNZLER; PRODANOV; PAREDES, 2009). Como afirmam Prado e Braga 
(2011, p. 187), foi preciso criar ações de marketing por parte das maisons e também trabalhos de sofisticação destes tecidos, para que fossem valorizados pelo público.

A partir destas ações, começaram a refletir os conceitos de "moda feita no Brasil" e, para atingir seus objetivos, a indústria têxtil precisou assumir a linha de criação de moda. Em 1958, surgiu a FENIT (Feira Nacional da Indústria Têxtil), um marco significativo no desenvolvimento do mercado (KUNZLER; PRODANOV; PAREDES, 2009). Após este período, a indústria têxtil, gradativamente, consolidou-se em solo nacional, com o surgimento de novas empresas, costureiros e também com a disseminação na mídia. Como afirmam Kunzler, Prodanov e Paredes (2009), no final da década de 70 a moda começa a ser propagada através das novelas - característica esta que observa-se comumente nos dias atuais.

A consolidação da moda nacional, por sua vez, se dá a partir dos anos 90. Segundo Prado e Braga (2011, p. 538), neste período se completou a cadeia de produção de moda brasileira, estimulada pela criatividade, qualidade e preços competitivos ao produto importado. Foi nesta década que o mercado brasileiro foi definitivamente visto como um negócio, já que os profissionais estavam, cada vez mais, buscando novos conhecimentos, inclusive acadêmicos (CHATAIGNER, 2010).

A moda brasileira traz na sua identidade raízes culturais históricas muito fortes e é a partir desta identidade que esta análise irá estudar o papel da publicidade como fator decisivo de construção.

\section{PROCEDIMENTOS METODOLÓGICOS}

Verificou-se a importância deste estudo quando, numa busca de dados na plataforma Scopus, de maio de 2016, obteve-se 316 artigos publicados contendo os termos fashion and advertising. A pesquisa foi focada em publicações nos últimos 10 anos e relatou que dos 316 documentos encontrados, $66 \%$ foram publicados como artigos, em sua maioria nos Estados Unidos. Sendo assim, busca-se, como referência para este trabalho, elevar os estudos envolvendo os termos moda e publicidade no Brasil.

Para compreensão acerca de como a publicidade vai influenciar a construção da identidade na moda brasileira, foi necessária uma pesquisa bibliográfica aprofundada sobre os paradigmas da moda e a publicidade e propaganda, suas origens e seu contexto histórico. O resgate bibliográfico ocorreu a partir de autores como Sant'Anna (2002), Sampaio (2003), Martins (1999), Lobassi (2016) e Cadena (2001), que discorrem sobre a publicidade, explicando seus conceitos e definições. Os autores Pollini (2007), Cidreira (2005), Spengler (1993), Palomino (2003), Cosgrave (2012), Lipovetsky (1989), Neira (2016) e outros foram utilizados para aprofundar os conceitos sobre moda.

A partir desse levantamento, buscou-se aprofundar os conhecimentos e analisar as campanhas da marca Ellus, de 1979 a 2016, definindo assim a abordagem da marca no mercado de moda e publicidade. Este procedimento da pesquisa teve natureza bibliográfica exploratória, como fase inicial do projeto. 
A análise deu-se a partir do estudo de caso da marca Ellus Jeans Deluxe que, segundo Yin (2001, p.21), é um método que contribui para a compreensão dos fenômenos sociais de uma maneira descritiva. As unidades de análise coletadas como produções audiovisuais e fotográficas, peças gráficas e o discurso institucional da marca serão analisadas e apresentadas para compor de forma clara a triangulação entre a construção das campanhas, a contribuição dos autores das áreas e a construção do cenário da moda e a publicidade brasileira.

\section{ANÁLISE E DISCUSSÃO}

A seguir, apresentam-se as análises e discussões sobre as campanhas da marca Ellus. Para tal, foram escolhidas cinco peças, sendo que, cada peça representa uma década, desde a fundação da marca até os dias atuais. Após uma pesquisa sobre as campanhas da marca em cada década, referenciam-se aquelas que mais obtiveram destaque para a marca. Não há, entre as peças analisadas, um critério de forma de veiculação característico, sendo as mesmas apresentadas em diferentes formatos, cada qual melhor representando o contexto histórico em que aconteceram.

\section{Discussão 01 - Comercial Mania de Você de 1979}

A campanha intitulada Mania de Você rodou no ano de 1979 e ainda é lembrada e consagrada por sua ousadia e coragem, visto que a campanha, que teve âmbito nacional, foi veiculada durante o período da ditadura militar. Além de anúncios em revistas, a campanha investiu também em comercial de TV, que será objeto de estudo desta análise.
O vídeo, com duração de 45 segundos, é intitulado Tire a Roupa para quem Você Gosta, mas, ficou nacionalmente conhecida pelo título da música tema, Mania de Você composta por Rita Lee e Roberto Carvalho. O vídeo inicia com um casal, que pula em uma piscina. O restante do comercial é rodado com o casal submerso. Os closes acontecem em pontos estratégicos das vestimentas, como nos zíperes, e nas etiquetas da marca presentes nas roupas, pois, segundo Cadena (2001), a etiqueta da Ellus era um objeto desejado e cobiçado pelos jovens da época. Os destaques também acontecem nas peças em jeans colorido, lançamentos da marca naquele ano (CADENA, 2001).

Além disso, a década de 70 foi de grandes discordâncias no meio publicitário. Os anos foram marcados pela censura dos militares, mas em contrapartida surgiram premiações, tanto nacionais quanto internacionais, no meio criativo (CADENA, 2001). Foi nesta década que a Ellus surgiu, com toda sua ousadia e irreverência, renovando os conceitos de marca e mergulhando de cabeça no mercado publicitário, numa época em que, como afirma Marcondes (1995, p.79) a propaganda deixou de ser uma arte para se tornar um negócio.

Mania de você foi veiculada em plena Ditadura Militar. A campanha, por conta de sua sensualidade e ousadia, era provocativa e ganhou repercussão e debates, inclusive no programa Fantástico. Mais precisamente, o ano de 1979 consistiu no apogeu da marca Ellus, sendo sua proposta acompanhar a moda com transgressão e ousadia, quebrando paradigmas e refletindo traços da contracultura europeia (CADENA, 2011). 
Outro fator histórico muito importante durante a década de 70 , e que influenciou no sucesso da campanha, foi o surgimento da TV em cores (CADENA, 2001). O comercial foi produzido todo em cores, dando assim destaque às peças em jeans colorido, podendo apresentar ao público a real proposta da coleção.

No campo da moda, os anos 70 foram de transformação. Segundo Prado e Braga (2011, p. 406), este período se transitou do glamour da alta moda para uma moda produzida em série, independente de possuir ou não grife. A Ellus vivia seus primeiros anos como marca e já havia se tornado produto de desejo entre os jovens da época. O jeans, peça em que a marca investiu fortemente, era considerado um vestuário de contestação e alienação e conquistou a todos os estilos (CHATAIGNIER, 2010).

Não é à toa que Mania de Você

foi um dos maiores comerciais da década de 70, a campanha levou o prêmio Profissionais do Ano, da Rede Globo. Ousado, envolvente, e, claro, corajoso. Tendo em vista o momento em que o país estava vivendo, bater de frente com a censura militar era tudo o que a grande maioria dos jovens daquela época desejava. O comportamento transgressor, apresentado na campanha, foi ponto importante para a marca obter este posicionamento até hoje. Além de tudo, a ousadia da campanha rendeu debates e mídia espontânea em outros meios de comunicação, e fez com que o produto fosse almejado - ainda mais - pelo público alvo.

\section{Discussão 02 - Inverno 1987 com Luma de Oliveira}

Para o inverno de 1987, a Ellus Jeans escolheu como rosto a top Luma de Oliveira, na época, iniciando sua carreira. A jovem, que estava conquistando o país com seu rosto, tinha o ar de liberdade e refletia as meninas da época: cabelos volumosos, sobrancelha mais grossa e rosto de menina.

A campanha possui um estilo minimalista, destacando apenas a modelo e a vestimenta, sem mais nenhum elemento. A modelo vestia uma roupa mais fechada - visto que a campanha veiculava no inverno - em tons escuros. A jovem estava encoberta por uma jaqueta jeans, com uma lavagem, para a época, moderna e inovadora. Apesar de ser uma peça muito simples, a campanha ainda assim apostava em sensualidade e juventude. A partir dos anos 80 a publicidade trocou a sua linguagem, até então comercial e direta, para uma linguagem persuasiva e também visual (SILVA; LOPES, 2007).

Os anos 80 foram responsáveis pelo apogeu da moda jovem, que logo foi disseminada para todos em peças como jeans, camisetas, bermudas, entre outras (PRADO; BRAGA, 2011). O estilo mais descolado e alternativo também foi destaque na época. Ganharam expressão estilos como o punk, o gótico e o new wave (PADRO; BRAGA, 2011).

A década de 80 também foi considerada como a década do Jeans. Segundo Prado e Braga (2011, p. 467): "Na década de 80 os produtos confeccionados em denim indigo blue atingiram um vulto quantitativo e uma variedade tão expressiva que, é possível afirmar, dominaram o mercado de roupas prontas no Brasil." Sendo o jeans a grande aposta daquele período, o destaque da campanha acontece justamente em uma peça nesse tecido, mostrando a variedade da sua usabilidade, sendo escolhida uma jaqueta nesse tom. Em contrapartida, nesta época 
também se utilizavam materiais alternativos, com acabamentos inovadores (PRADO; BRAGA, 2011), e com o destaque da jaqueta, o acessório de pelos no interior da peça também se torna um elemento forte na imagem.

O editorial, de forma simples e clara, conseguiu repassar o conceito da marca para seu público. Apesar de não ter grandes produções, e também não estar produzida de forma surpreendente, a campanha conseguiu adequar peças desejo da época, com estilo e, ainda, certo tom de sensualidade. Utilizar o rosto de Luma de Oliveira foi o ponto chave da campanha. A jovem, na época, era um dos rostos promissores e muitas jovens gostariam de ser como a top, causando identificação do público alvo.

\section{Discussão 03 - Verão 1999 com Milla Jovovich}

A campanha de verão de 1999 foi icônica para a marca. Como rosto principal da campanha, estrelou a modelo e atriz internacional Milla Jovovich. As fotos foram registradas pelo renomado fotógrafo inglês Tom Munro e o cenário escolhido por ele mesmo foi o Sul da França. O objetivo do cenário era garantir frescor, liberdade e positividade, elementos que eram propostas principais da campanha. Toda a campanha foi fotografada em preto e branco, e as imagens refletem o lúdico, a beleza e o frescor da modelo, sem perder o apelo sensual, característico das campanhas da Ellus (ELLUS, 2016).

A campanha reflete exatamente a tranquilidade de um casal, em um cenário interiorano. É, contudo, uma campanha leve, com imagens simples e pouca manipulação digital, apostando apenas nas imagens em preto e branco e no jogo natural de luz e sombra. O comportamento transgressor, outra característica da marca, não está exposto na campanha, que, por sua vez, reflete suavidade.

A campanha da Ellus para o inverno de 1999 foi uma campanha bem elaborada, com locação, modelos e grande parte das equipes internacionais. Contudo, neste período, o mercado ainda estava em recuperação. Apesar do avanço tecnológico, o início da década de 90 é marcado pela crise econômica e também pela crise cultural, e sem medo, a proposta da Ellus foi inovação, a marca investiu em uma campanha com parâmetros internacionais em tempos de recuperação.

Nos anos 90 que surgem as primeiras gerações de estilistas e profissionais graduados nas primeiras escolas do setor (PRADO; BRAGA, 2011). Chataignier (2010, p.166) afirma que a abertura das importações desmereceu o mercado nacional que, em contrapartida, viu como necessária a renovação tecnológica da indústria, dando valor ao marketing e a publicidade. Por conta desta valorização é que, mesmo diante de um período de recuperação, a Ellus resolveu investir em uma campanha tão grande. Apesar de ter sido considerada uma campanha icônica para a Ellus, por conta de sua estrutura em grande parte internacional, a peça foge um pouco dos padrões utilizados pela marca. A sensualidade persiste, porém, não está demonstrada de forma transgressora ou inovadora, mas sim, como uma sensualidade romântica. No entanto, foi uma campanha minimalista, forte e de sucesso.

\section{Discussão 04 - Inverno 2006 com Letícia Birkheuer}

A top Letícia Birkheuer foi o rosto da campanha de inverno 2006 da Ellus, juntamente 
com o modelo Mauro Salvatore, com imagens capturadas pelo fotógrafo Jacques Dequeker (ANDERSON, 2006). A campanha fugiu do tradicional, investiu na área gráfica e foi premiada por conta das ilustrações presentes na campanha, criadas por Andrés Sandoval.

As ilustrações têm o objetivo de tornar a modelo uma mulher pássaro, através de elementos desenhados. Embora estejam na mesma imagem, o casal aparenta estar em contextos diferentes, dando um sentido ambíguo à imagem. De um lado, observa-se o modelo, sentado em uma cadeira, com vestimenta social. Do outro, a modelo, que representa uma mulher pássaro, vestindo um vestido preto com alças sobrepostas. Na imagem da modelo, percebem-se as ilustrações de Sandoval.

A modelo está toda ilustrada, enquanto o modelo se apresenta naturalmente. Todo este jogo faz com que se tenha a impressão de que a imagem é uma montagem, ou, até mesmo uma colagem, dando um sentido à ilustração. A campanha teve premiação como a melhor campanha do ano no $57^{\circ}$ Premier Print Award. Este prêmio acontece em Chicago, nos EUA, e é o maior prêmio da indústria gráfica (ANDERSON, 2006).

A campanha não foge à realidade das demais produzidas pela Ellus. A sensualidade, característica fixa da marca, é percebida, mesmo que de forma sutil, na maneira em que os modelos se vestem e em que estão posando para as imagens. A intenção de demonstrar liberdade - e provocar este desejo - está explícito através da demonstração dos pássaros, que estão libertos da gaiola. Ao analisar a peça, a sensação que transparece é que o pássaro principal, neste caso retratado pela modelo, é que provocou esta liberdade.

A campanha foi veiculada no ano de 2006, primeira década do milênio marcada pelo avanço da tecnologia, e a informática se tornando indispensável para finalização de peças, pois aprimorava o produto final (CADENA, 2001). Percebe-se que, na peça analisada, foram utilizados recursos tecnológicos para a finalização, com ajustes de cores, montagem de elementos e, claro, nas ilustrações. A peça é elevada a um nível de sofisticação - percebe-se ao observar as peças anteriores - por conta destes recursos.

Não somente no campo da publicidade é que a tecnologia se desenvolveu ao longo do novo milênio. A tecnologia têxtil muda a maneira de criadores e confeccionistas de produzirem (CHATAIGNER, 2010). As vestimentas, como se percebe na imagem do anúncio, mudam seu recorte e também trazem um lado mais sensual. Como afirma Chataigner (2010, p.181), nos anos 2000 surge uma espécie de cópia do que já se passou, porém, com um aumento de sedução que se dá de várias maneiras, seja através de superposições ou de tecidos que dão caimento.

\section{Discussão 05 - Digital Wave - Verão 2017}

Para o verão 2017 a Ellus criou a campanha Digital Wave. Para esta coleção, a proposta da marca é apresentar inspirações do Havaí, mescladas a ousadia rocker, adicionando, claro, um conteúdo moderno por conta das ondas digitais. São investidos em peças digitais, na sua grande maioria, em evidência ao mote da campanha. Para a análise, contudo, servirá como objeto de estudo um dos fashion films elaborados para a página no Facebook da Ellus. 
O fashion film possui duração de 15 segundos e é apresentado em formato HD. Apesar de trazer o mote praiano, não foi utilizado nenhum elemento da natureza para o cenário, nem ao menos uma locação externa. O filme é gravado em estúdio, com uma tela ao fundo. Todas as imagens das telas são apresentadas ainda com uma textura linear, o que faz com que a imagem remeta justamente ao digital.

Ao decorrer das cenas, os modelos intercalam as vestimentas, compostas por três tipos, sendo elas: em tons terrosos e verde militar, em tons vermelhos e estampas havaianas e, por último, o clássico jeans Ellus. As cenas são alteradas com cortes bruscos, seguindo as batidas da trilha sonora. Esta trilha, por sua vez, é uma batida eletrônica, que lembra os bytes de navegação da internet. Os modelos, ora estão com um conjunto de roupas, ora com outro, compondo o jogo de cenas. No último take, seis dos sete modelos se organizam em linha, intercalando homem e mulher, todos vestindo o look jeans Ellus.

A campanha esbanja sensualidade, desenvoltura e postura dos modelos além, claro, dos trajes de banho abaixo dos trajes tradicionais. A trilha sonora, mesmo fazendo referência a algo digital, ao combinar com os cortes das imagens, também remete ao poder e à sensualidade, pois se adéqua à postura dos modelos.

O filme apresenta ousadia e combinação de trazer algo totalmente natural, como as características havaianas, com o digital, que é algo tão artificial, e mostrou que esta ousadia, mais uma vez, foi assertivo para a Ellus. Ao analisar as demais campanhas, percebe-se que a marca cultivou suas principais características desde o início, estando, porém, sempre à frente de seu tempo e inovando com tecnologias, novas propostas e muita ousadia.

Assim como no início da década, a tecnologia continua sendo um item indispensável nas produções publicitárias (CADENA, 2001). Contudo, a tecnologia se torna cada vez mais aperfeiçoada, possibilitando novos recursos para a reprodução das peças, principalmente em filmes. A produção fotográfica e artística se torna mais sofisticada e é grande a diversidade e facilidade da manipulação destas imagens (SILVA; LOPES, 2007).

$\mathrm{Na}$ indústria têxtil, a inovação também continuou constante, com novas tecnologias, cortes e tecidos. Percebem-se estes novos tecidos, bem como novos recortes do jeans, tecido de maior destaque da marca desde sua criação, nas vestimentas dos modelos. A maioria das roupas dos modelos possui referenciais principalmente dos anos 80 , como as jaquetas em modelos jeans e bomber (CHATAIGNER, 2010).

Digital Wave é uma peça que segue a linha de criação da marca Ellus. Ela é forte, poderosa, reflete muita sensualidade e está à frente do seu tempo. Contudo, visto os avanços tecnológicos e culturais da sociedade, esta peça é destaque entre as demais, pois possui um esforço de criação avançado. A campanha é completa e é uma das mais fortes no quesito presença digital, tendência esta que promete seguir forte. Apesar de ser uma peça bem finalizada, sua produção não necessitou de grandes esforços externos, como locação externa, entre outros. A criatividade de lançar uma coleção misturando elementos havaianos, redesenhados de forma a remeter ao lado tecnológico, foi outro ponto criativo da coleção verão 2017 da Ellus e mostra, também, a capacidade de inovação da marca. 


\section{CONSIDERAÇÕES FINAIS}

Este ensaio questiona de que forma a publicidade pode contribuir para a construção de identidade na moda brasileira. Para tal, a partir do estudo de caso realizado da marca Ellus, percebe-se a ligação entre os mercados de moda e publicidade. A grife brasileira acompanhou desde o início as transformações do setor têxtil, além disso, sempre investiu fortemente em campanhas publicitárias, sendo referência nos dois setores. Esta dualidade possibilitou a triangulação dos dados históricos de moda e publicidade e foram cruciais para o contexto e para disseminar o vínculo entre as duas áreas, principalmente no Brasil.

Observou-se através das análises das campanhas da década de 70 aos anos 2017, que todas as campanhas demonstram um reflexo no público alvo, apresentando tudo o que eles acreditam e idealizam, disseminando, assim, o desejo nas peças da marca e o reflexo da ideologia da mesma. Os jovens eram impactados pelas campanhas, não apenas pela roupa que elas ofereciam, mas também pela ideologia que defendia. Assim sendo, o público, que se identifica com a ideologia da marca, acaba por escolher consumir seus produtos e tudo isto graças à campanha publicitária da qual foram impactados.

\section{REFERÊNCIAS}

ANDERSON, Chris. A Cauda Longa: do mercado de massa para o mercado de nicho. Rio de Janeiro: Elsevier, 2006. $240 \mathrm{p}$.

CADENA, Nelson Varón. Brasil: 100 anos de Propaganda. $1^{a}$ ed. São Paulo: Referência, 2001.

CHATAignier, Gilda. História da Moda no Brasil. $1^{a}$ ed. São Paulo: Estação das Letras e Cores, 2010.
COSGRAVE, Bronwyn. História da indumentária e da moda: Das antiguidades aos dias atuais. $1^{\mathrm{a}} \mathrm{ed}$. Barcelona: Gustavo Gili, 2012.

\section{ELLUS. Relembre Milla Jovovich no verão da} Ellus 1999/00. Disponível em:

$<$ http://ellus.com/salaellus/tag/campanhas-ellusantigas/>. Acesso em: 16 de outubro de 2016.

\section{FAÇANHA, Astrid. Moda Brasileira 1930.}

Disponível em:

$<$ http://gowheresp.terra.com.br/24/24historiamoda.ht $\mathrm{ml}>$. Acesso em: 21 de agosto de 2016.

KUNZLER, Juliana Rossi; PRODANOV, Cleber Cristiano; PAREDES, Carlos Henrique Miranda. Da Utopia a Realidade: em Busca da Construção Histórica de um Conceito de Moda Brasileira. Disponível em:

$<$ http://www.historiaehistoria.com.br/materia.cfm?tb= artigos\&id=92> Acesso em: 21 de agosto de 2016 .

LIPOVETSKY, Gilles. O império do efêmero: a moda e o seu destino nas sociedades modernas. $1^{\text {a }}$ ed. São Paulo:Companhia das Letras, 1989.

\section{LOBASSI, Edmundo W. Histórico da Mídia no Brasil. Disponível em: \\ $<$ http://www2.anhembi.br/html/ead01/estrategias com _midia_eletronica/aula1.pdf $>$. Acesso em: $27 \mathrm{de}$ agosto de 2016.}

MARCONDES, Pyer; RAMOS, Ricardo. 200 anos de propaganda no Brasil: do reclame ao cyber-anúncio. $1^{a}$ ed. São Paulo: Meio \& Mensagem, 1995.

MARTINS, Zeca. Propaganda é isso aí! - Um guia prático para novos anunciantes e futuros publicitários. $2^{\mathrm{a}}$ ed. São Paulo: Futura, 1999.

NEIRA, Luz Garcia. A Invenção da Moda

Brasileira. Disponível em: <www.revistas.usp.br>. Acesso em: 17 de maio de 2016.

PALOMINO, Erika. A moda. $1^{\text {a }}$ ed. São Paulo: Publifolha, 2003.

POLLINI, Denise. Breve História da Moda. $1^{\mathrm{a}}$ ed. São Paulo: Claridade, 2007.

PRADO, Luís André do; BRAGA, João. História da Moda no Brasil: Das influências às autorreferências. $2^{\mathrm{a}}$ ed. São Paulo: Disal, 2011. 
SANT'ANNA, Armando. Propaganda: Teoria, Técnica e Prática. $7^{\mathrm{a}}$ ed. São Paulo: Cengage

Learning, 2002. 